\title{
DESCONTRUINDO DISCURSOS ACERCA DAS NOÇÕES DE SUSTENTABILIDADE E DE DESENVOLVIMENTO
}

\author{
João Rua \\ Departamento de Geografia da PUC-Rio \\ joaorua@uol.com.br
}

Pontuarei minha reflexão em três momentos: o primeiro sobre Geografia; depois, em um segundo momento, no espaço geográfico; e no terceiro momento sobre essa idéia de desenvolvimento e de sustentabilidade. Adianto, desde já, que prefiro falar em desenvolvimentos, no plural, e sustentabilidades, no plural também, na medida em que percebo que é na trama ecológica da vida, como diz o geógrafo David Harvey (2004), que é localizada e que é o real (integrado escalarmente em outras dimensões da ação política e social), que eu construo a minha reflexão, a qual está ligada, em certa medida, à Geografia Política do meio ambiente.

Como é que eu encaminho isso, em primeiro lugar pensava que a geografia nasceu holística, se usava esse termo no século XVIII e XIX pelos "pais fundadores" da Geografia. Humboldt e Ritter eram pelo seu romantismo, no século XIX, holísticos; viam a natureza e a sociedade integradas. Aquela visão de integração constitui a primeira definição de Geografia como ciência cimeira juntando as duas dimensões, pouco a pouco foi caindo, porque a sociedade toda - e a ciência em geral e em particular - com o positivismo da segunda metade do século XIX foi se afunilando, foi se especificando e é nessa especialização que surge hoje como marca da ciência ocidental, que não consegue participar de uma análise em que se privilegie, simultaneamente, a parte singular e a totalidade.

Atualmente, pensamos na medicina e já não temos “apenas" um oftalmologista, agora é um especialista de córnea ou de nervo ótico. A análise mais generalista foi caindo, na medida em que se privilegiou a especialização, e essa fragmentação atingiu profundamente a Geografia, que não nasceu dicotômica, mas que se tornou dicotômica para seguir os rumos da docência que foram se tornaram dicotômicas. É só pensar na Antropologia, que nasceu Antropologia Física e Antropologia Cultural, somente depois é que a física foi deixando de existir e agora, hegemonicamente, passou a ser cultural. Se olharmos para a Biologia, perceberemos que ela nasceu Biologia Humana, a 
Geologia se fragmentou, enfim todas passaram por esse processo. Não temos que ter complexo de inferioridade por isso, temos que pensar em que momento nós estamos.

Esse momento, que já vivenciamos há uns 30 anos, tenta resgatar esse discurso mais integrador, pois aquilo que antes era visto como generalismo faz falta. A medicina restaura o papel do clínico geral, que hoje é um médico conceituado. A Geografia começa a ter certa percepção diferente daquela que vinha tendo, geógrafos começam a desenvolver um discurso mais integrador do espaço multidimensional, que é ao mesmo tempo físico-material, socioeconômico, político-adminitrativo, simbólico-cultural.

Aqui vemos as dimensões e, eventualmente, para efeitos didáticos podemos privilegiar algumas dessas dimensões, uma em relação às demais, mas não devemos esquecer daquilo que não estamos privilegiando; ou seja, das múltiplas dimensões do espaço.

A primeira idéia que queremos deixar registrada é pensar multidimensionalmente o espaço. O espaço é uma totalidade multidimensional, é uma totalidade, mas nunca está completa; já ouvimos dezenas de vezes isso, o geógrafo Milton Santos (1996) falou seguidamente isso: a totalização é um processo de totalização, portanto um espaço multidimensional tem movimento. Denomino este movimento de desenvolvimento, que não é sinônimo de crescimento econômico. Só que essa multidimensionalidade do espaço se manifesta nas distintas parcelas desse espaço de maneira diferente, mas tudo isso integrado naquele movimento de totalização.

O movimento é desigual e cada parcela desse espaço tem um ritmo, tem características locais. As contradições desses locais, jogos, atores políticos, sociais, e cada lugar em cada área, em cada área maior, em diferentes escalas, e que interagem verticalmente com as escalas superiores, mas também horizontalmente de um lugar para o outro, aqueles lugares que mais se destacam em relação a outros lugares acabam hegemonizando os outros. Portanto, o movimento do desenvolvimento é desigual e combinado, pois está indo na mesma lógica, na mesma direção. E é aí que queremos registrar como faremos a construção, embora saibamos que não teremos como fazê-lo neste breve debate, mas a idéia é essa: o espaço é multidimensional, então a totalização é um movimento e a esse movimento pode se chamar de desenvolvimento, que é desigual nas parcelas do espaço, mas é combinado pela mesma lógica, e a lógica é de cada momento, e é presidida há mais de 100 anos pelo capitalismo.

Não restringimos o capitalismo à ideia de modo de produção apenas no viés econômico, vemo-lo como um modo civilizacional, porque já atravessa todas as dimensões do viver de cada um de nós. Ao atravessar nosso viver cotidiano, nos afeta diretamente não 
apenas na produção, mas na reprodução de nossa vida social, política, econômica, simbólico-cultural, portanto esse espaço multidimensional também é híbrido, híbrido de componentes naturais e humanos. Como vimos, a dimensão físico-material não é mais nem menos importante e é aí que gostaríamos de chamar a atenção para o fato da Geografia tentar construir a idéia de que o espaço é transformado em território, porque essas desigualdades, essas assimetrias entre as diferentes parcelas do espaço estão integradas aos jogos de poder e vão afetar tanto ações entre os seres sociais quanto as relações do humano com o não humano, incluindo aí todas as dimensões do físicomaterial que as vezes não é só o material.

A geografia participa ativamente do debate sobre desenvolvimento e sustentabilidade e suas relações no espaço com o poder, portanto formando territórios e territorialidades diversas. O lugar, essa particularidade diversa, apresenta-se como diferencial para o capital com novas formas de negociação. Como diz a geógrafa Doreen Massey (2005), negociações com sujeitos locais embora de maneira assimétrica e aí temos um problema para entender. Além desse jogo complicado entre parcelas desigualmente desenvolvidas mas combinadas, ainda tem um outro jogo, o jogo de qual é a lógica desse capitalismo entendido como processo civilizatório do momento, que é entendido como uma lógica de desconcentração (em outras épocas, até 20 anos atrás, havia uma lógica de concentração, em que metrópoles, aglomerações urbanas, megalópoles, complexos urbano-industriais era vigente).

Hoje, trata-se de uma lógica de dispersão, de desconcentração, e essa lógica de dispersão é uma lógica que vai afetar todas as dimensões da vida individual, social, estatal. Tal desconcentração vai trazer esse jogo direto para nós, vai nos criar uma espécie de divisão territorial da degradação ambiental. Nessa transferência de degradação ambiental internacional ou divisão territorial da degradação ambiental e nesse processo de desconcentração são os países centrais os que mais poluíram, aqueles que mais interferiram na dinâmica planetária em termos de sociedade-natureza, integrando essa lógica de capitalismo de investimento, da indústria, procurando um lugar de mão de obra mais barata, os locais mais acessíveis e de legislações mais permissivas para a instalação de indústrias mais poluentes. Atividades extrativistas tem contribuído para uma desconcentração mundial, uma periferização dessa degradação. Como lá nos países centrais a legislação é mais rígida, há mais controle sobre isso, os países periféricos acabam sendo uma opção interessante para o empresariado. 
As relações capital-trabalho são livres na maior parte do mundo, as relações de trabalho estão cada vez mais desregulamentada e há mais exploração. Então, esse jogo de transferência de degradação ambiental internacional também é um dado importante na discussão de desenvolvimento e sustentabilidade, porque se o desenvolvimento não é só crescimento econômico, como temos sempre frisado, esse movimento todo no espaço agrega relações de poder, que fazem com que uma parcela do espaço expresse mais poder do que outras. Trata-se de um jogo de poder dos atores sociais mais hegemônicos e que também podem, inclusive, chantagear lugares como os industriais da CSA, na Zona Oeste.

Acreditamos que a Geografia deve contribuir para outra ética territorial, porque essas espacializações, esses jogos de poder, produzem territórios totalmente diferenciados uns dos outros, nos quais esses jogos de poder se estabelecem de maneira diferente em cada uma das parcelas diferentes do espaço em movimento. Trata-se de pensar em uma concepção da relação sociedade-natureza que passe também por essa multidimensionalidade do território. Falamos de relações de poder, trata-se da dominação de recursos da terra, limitações, das condições de reprodução humanas que são permanentemente atacadas por esse jogo de dominação da mercadoria, por esse jogo assimétrico em que uns teriam mais forças do que outros.

Segundo Harvey (2004), trabalhando com a idéia de desenvolvimentos geográficos desiguais, que resultam da aproximação de diversos momentos, da cooperação de fases distintas (em que a História Ambiental pode entrar perfeitamente), das interações espaciais e sociais com agentes naturais em suas dimensões materiais e imateriais, desiguais e contraditórias que marcam o território. Acreditamos que a partir dessa visão de desenvolvimentos geográficos desiguais, cada parcela do espaço geográfico deve ter o direito de que seus atores sociais definam seu próprio desenvolvimento, ao contrário de ter que seguir determinado modelo de desenvolvimento.

O que é bom para os EUA ou para a Alemanha não necessariamente o é para todos. Da mesma maneira que a resistência a esses movimentos tem de ser particular, então o jogo é muito mais complexo do que essa uniformização forjada pelos pretensos poderes hegemônicos, os chamados poderes da globalização que propõem discursos homogeneizantes para todo o planeta, desrespeitando a diferença e a diversidade. Transformam essa diversidade em desigualdade. em que algumas parcelas são mais privilegiadas do que as outras. 
Se o desenvolvimento é concebido como crescimento, já é insustentável. A expressão sustentável é um adjetivo que veio salvar aquela coisa que já estava condenada. Sustentabilidade não é só mico-leão-dourado, o projeto já apresentou aqui diversas sustentabilidades. A sustentabilidade é ecológica, política e social, então essas sustentabilidades que vários autores vêm trabalhando, tentamos trazer para a Geografia, percebendo-as na sua âncora territorial, na sua âncora espacial, em cada parcela do espaço, mas que são diferentes das demais. Nós enquanto atores acadêmicos engajados e como professores, principalmente, lutamos para que essas diferenças não sejam entendidas como desigualdades, em que uns são melhores que os outros; as diversas hierarquias que vem desde as hierarquias planetárias, que vem desde o ocidente pelos EUA em relação com o resto do mundo. Temos de combater fundamentalmente essa hierarquização, porque essa hierarquização vai atingir inclusive a dinâmica natural, essa dimensão físico-material do espaço pelo território, na medida em que a natureza natural vai ficando subalternizada, vista apenas como recurso a ser transformado em riqueza; nada mais do que isso.

Não vai ser útil por mais que ainda subsista um discurso sustentável, ecológico, mas os tomadores de decisões que tem o poder econômico não pensam assim, eles só vêem os recursos naturais como possibilidade de riqueza; e pior de tudo, nos últimos 40 anos transformaram o próprio ser humano em uma coisa horrorosa, aquilo que se chama de recursos humanos, que também são potenciais de riqueza que tem a possibilidade de gerar riqueza com a força de trabalho, através da reprodução social das pessoas.

O território é fundamental para nós trabalharmos objeto. Não se trata da idéia de sustentabilidade territorial em que o conceito de território é algo fixo, pré determinado, delimitado e sem movimento, pois se temos um território imitável, estamos presos, vivendo em uma armadilha em que vemos tudo a partir dali. Com isso, o território precisa ser analisado como fluido, sendo multiescalar, não ficando aprisionado a essas escalas fixas do poder político.

Precisamos pensar em multissustentabilidades integradas às medidas territoriais e ao multidesenvolvimento, em consideramos a multiescalaridade da ação política integrando os conflitos e resistências aos modelos econômicos, e as sustentabilidades territoriais integrando a muldimensionalidade do território com as dimensionalidades do desenvolvimento e as dinâmicas que as animam.

Esta é nossa responsabilidade como professores, atuando como difusores de um outro discurso, que não seja este discurso da dominação, da heteronomia em que o físico fica 
subalternizado ao meio físico-material. Em que as dimensões sejam integradas, em que o social e o natural sejam uma coisa só, sejam componentes do espaço geográfico.

Sempre que oriento trabalhos de Geografia Física fora e dentro do departamento, afirmo que o problema não é físico, o problema é social, o físico é a dinâmica, é a dinâmica da natureza. Com isso eu não posso dizer que é o problema, faz parte da evolução ou coevolução, então essa mesma relação faz parte e é um problema social. Por exemplo, a casa está desabando, se tem uma pousada que é construída no alto de uma encosta acelerando a fragilidade, estamos falando também de ações especulativas. Com isso, vemos que o problema está aí, você é parte desse problema, pois é um problema social, é a dinâmica que está fazendo parte daquele problema, aí entra a Geomorfologia, a Botânica, dependendo do foco que se vai escolher. O trabalho é fechado resgatando a interação e mostrando como essa mesma interação não e percebida pelos planejadores, pela academia ou é negligenciada e não é percebida por nós no nosso viver, de tal forma que nós somos martelados pela mídia, pela forma, pela fragmentação, pelas representações que são construídas e nos são tributadas permanentemente. Acatamos por desconhecer essa dinâmica, que é riquíssima e que é a dinâmica que nos leva a compreender o espaço.

Essas preocupações da Geografia nos encaminham para a consideração de um múltiplo desenvolvimento e múltiplas sustentabilidades em escalas de análises da ação política na construção de uma autonomia que ative a capacidade de participar de maneira ativa, com capacidade de organização e luta, a partir dos conflitos a que nos referimos antes, e conscientes dos rumos que devem ser seguidos pela comunidade na qual o individuo faz parte, integrando as escalas do poder e saber, levando a uma gestão democrática do território, em que não haja excluídos ou incluídos precariamente, em que o espaço banal, onde vivenciamos o cotidiano, seja um espaço de comunhão, de comunicação, que seja o lugar de todos, como desejou o professor Milton Santos em seus vários trabalhos.

\section{Referências}

HARVEY, David. Espaço de Esperança. São Paulo: Loyola, 2004.

MASSEY, Doreen. Pelo Espaço. Rio de Janeiro: Bertrand Brasil, 2005.

SANTOS, Milton. A natureza do espaço. São Paulo:Hucitec, 1996. 